\title{
ANALISA DAN PERANCANGAN SISTEM PENINGKATAN POTENSI DESA (Studi Kasus JI. Sentra Desa Mulyoharjo, Kecamatan Jepara)
}

\author{
Hikmah Rossyta Virgiannada, Yusuf Amrozi \\ Universitas Islam Negeri Sunan Ampel \\ rossytahikmah2@gmail.com
}

\begin{abstract}
Utilization of village potential can have a big influence on the village itself and for the community. This cannot be realized only by village officials or a handful of people, but all those involved in the village. The role of adolescents is very emphasized in this development, but various problems such as lack of skills possessed, limited education obtained result in a feeling of lack of confidence which ultimately inhibits the development of the potential of a village, therefore a place is needed to develop or enhance village potential. Analysis and design of the village potential enhancement system helps in increasing community skills, which can support the potential that exists in the village.
\end{abstract}

Key word: potential, village, Mulyoharjo, Jepara

\begin{abstract}
Abstrak
Pemanfaatan potensi desa dapat berpengaruh besar terhada desa itu sendiri maupun bagi masyarakat. Hal tersebut tidak dapat diwujudkan hanya oleh perangkat desa atau segelintir orang saja, melainkan semua yang terlibat di dalam desa tersebut. Peran remaja sangat ditekankan dalam pengembangan ini, namun berbagai masalah seperti kurangnya keterampilan yang dimiliki, keterbatasan pendidikan yang didapat mengakibatkan munculnya rasa kurang percaya diri yang akhirnya menghambat berkembangnya potensi suatu desa, oleh karena itu diperlukan sebuah wadah untuk mengembangkan atau meningkatkan potensi desa. Analisis dan perancangan system peningkatan potensi desa membantu dalam menambah skill masyarakat, yang dapat mendukung potensi yang ada pada desa.
\end{abstract}

Kata kunci: potensi, desa, Mulyoharjo, Jepara

\section{PENDAHULUAN}

Menurut Peraturan Pemerintah Nomor 72 Tahun 2005, Desa adalah kesatuan masyarakat hukum yang memiliki batas-batas wilayah yang berwenang untuk mengatur dan mengurus kepentingan masyarakat setempat, berdasarkan asal usul dan adat istiadat setempat yang diakui dan dihormati dalam system Pemerintahan Negara Kesatuan Republik Indonesia.

Potensi desa merupakan segala sumberdaya alam maupun sumberdaya manusia yang terdapat serta tersimpan di desa. Di mana semua sumberdaya tersebut dapat dimanfaatkan bagi kelangsungan dan perkembangan desa. Dalam studi kasus yang diangkat, Desa Mulyoharjo telah ditetapkan sebagai desa wisata sentra industri yang berarti telah ditemukannya potensi pada desa tersebut. Namun perkembangan yang terjadi masih dapat ditingkatkan agar lebih maksimal.
Masalah yang ada dalam desa yaitu banyaknya masyarakat terutama remaja hanya bekerja dengan mengandalkan tenaga seperti angkat junjung, mengamplas menggunakan mesin dan lain sebagainya, dan hanya berfokus pada pekerjaan yang butuh tenaga. Yang mana dalam sebuah industri banyak hal yang pasti dibutuhkan dan mempunyai posisi lebih tinggi seperti akuntansi, desainer, marketing, sampai admin. Adapun skill lain yang dibutuhkan namun banyak remaja kurang minati seperti mengukir dan nukang, dengan alasan malas untuk mempelajari karena lamanya proses belajar yang otomatis juga lamanya tertundanya mendapat gaji. Tidak ada kesadaran mengenai pentingnya semua skill itu untuk di kemudian hari, yang mana tidak akan ada rasa menggantungkan diri pada satu pekerjaaan, dapat memulai bisnis sendiri. Hal- hal seperti 
ini perlu lebih digali dan ditingkatkan untuk mengembangkan potensi suatu desa.

Sistem peningkatan potensi desa berperan dalam pengembangan skill yang sesuai dengan potensi yang dimiliki oleh desa, system ini menjembatani pembelajaran skillskill penting untuk peningkatan potensi desa. Dalam studi kasus Desa Mulyoharjo skill yang sesuai untuk dikembangkan adalah akuntansi, desain grafis, teknik marketing, Microsoft Office, web dan internet, nukang dan ngukir. Skill ini dibutuhkan dalam desa mulai dari tahap produksi sampai tahap pemasaran. Sistem ini dibutuhkan kesadaran dari masyarakat untuk saling tolong menolong dalam peningkatan potensi desa maupun pengembangan SDM yang ada dalam desa.

\section{METODE}

\section{Metode Pengembangan Sistem}

Untuk pengembangan system penelitian ini menggunakan model sdlc (software development life cycle). Model sdlc yang dipakai dalam penelitian ini adalah model waterfall, waterfall model atau classic life cycle. Metode waterfall adalah metode yang menyarankan sebuah pendekatan yang sistematis dan sekuensial melalui tahapantahapan yang ada untuk membangun sebuah perangkat lunak.

Metode atau tahap-tahap dalam pengembangan sistem menggunakan metode waterfall yang meliputi:

\section{Requirements analysis and definition requirements analysis and definition}

Mengumpulkan kebutuhan secara lengkap. Kemudian dianalisis dan didefinisikan kebutuhan yang harus dipenuhi oleh program yang akan dibangun. Fase ini harus dikerjakan secara lengkap untuk bisa menghasilkan desain yang lengkap.

\section{System and software design}

Desain dikerjakan setelah kebutuhan selesai dikumpulkan secara lengkap. Tahap ini dilakukan sebelum melakukan coding. Tahap ini bertujuan untuk memberikan gambaran apa yang seharusnya dikerjakan dan bagaimana tampilannya.

\section{Implementation and unit testing}

Desain program diterjemahkan ke dalam kode-kode dengan menggunakan bahasa pemograman yang sudah ditentukan. Program yang dibangun langsung diuji baik secara unit.

\section{Integration and system testing}

Penyatuan unit-unit program kemudian diuji secara keseluruhan. Di tahap ini dilakukan penggabungan modulmodul yang sudah dibuat dan dilakukan pengujian untuk mengetahui apakah software yang dibuat telah sesuai dengan desainnya dan masih terdapat kesalahan atau tidak.

\section{Operations and maintenance}

Mengoperasikan program di
lingkungannya dan melakukan
pemeliharaan, seperti penyesuaian atau
perubahan karena adaptasi dengan situasi
sebenarnya. Kekurangan yang utama dari
model ini adalah kesulitan dalam
mengakomodasi perubahan setelah proses
dijalani. Fase sebelumnaa harus lengkap
dan selesai sebelum mengerjakan fase
berikutnya.

\section{Metode pengumpulan data}

Dalam mengumpulkan data penelitian, penulis melakukan dua metode penggumpulan data yaitu:

1. Observasi, dengan cara mengamati, mengumpulkan, mempelajari dan mencatat langsung tentang sistem pembelian sampai pembuatan laporan. Dalam metode ini setiap data dicatat langsung, sehingga dapat menghasilkan informasi yang tepat dan akurat

2. Studi pustaka, mengumpulkan teori-teori yang bersumber dari buku-buku serta jurnal-jurnal yang dapat mendukung penelitian ini.

\section{HASIL \\ Hasil Observasi}

Setelah dilakukan observasi pada Desa Mulyoharjo dengan mengambil sampling secara acak pada RT. 02 RW. 05 Mulyoharjo mendapatkan hasil sebagai berikut: 
a. Bagian Wilayah Mulyoharjo dikenal sebagai "Sentra Industri Seni Patung dan Ukir"

Namun seiring berkembangnya waktu, ukir di Desa Mulyoharjo mengalami penurunan yang cukup drastis dari segi peminat sampai penghasilan yang didapat. Beberapa tempat yang menjual sovenir dengan ukiran, diketahui sovenir tersebut berasal dari luar kota Jepara.

\section{b. Banyaknya industri furniture yang berkembang pesat}

Hal yang mencolok dari yang dikenal sebagai industri seni ukir dan patung, Mulyoharjo juga banyak ditemui hasil furniturenya, perpindahan profesi dari tukang ukir menjadi pengusaha furniture bukan hal yang mengherankan karena hasil yang didapat dari mengukir dan usaha furniture mempunyai signifikan yang besar.

\section{c. Kurangnya peran masyarakat}

Peran masyarakat sangat dibutuhkan dalam peningkatan potensi suatu desa termasuk Desa Mulyoharjo. Namun kendala yang terjadi, remaja kurang aktif dalam meningkatkan potensi diri maupun potensi desa. Hasil observasi pendidikan terakhir yang ada pada JI. Sentra 1 RT. 02 RW. 05 Mulyoharjo yang sebagian penduduknya berprofesi berkaitan dengan industri patung, ukir maupun furniture dengan mengambil masing-masing 10 orang berdasarkan rentang umur berdasarkan sampling random.

Tabel 1. Jumlah penduduk berdasarkan rentang umur

\begin{tabular}{|l|c|c|c|c|}
\hline $\begin{array}{c}\text { Rentang } \\
\text { Umur }\end{array}$ & $\begin{array}{c}\text { SD } \\
\text { (org) }\end{array}$ & $\begin{array}{c}\text { SMP } \\
\text { (org) }\end{array}$ & $\begin{array}{c}\text { SMA } \\
\text { (org) }\end{array}$ & $\begin{array}{c}\text { Sedang/ } \\
\text { lulus PT } \\
\text { (org) }\end{array}$ \\
\hline $18-25$ & & & 6 & 4 \\
\hline $25-40$ & 1 & 7 & 2 & \\
\hline $35-$ atas & 9 & & 1 & \\
\hline
\end{tabular}

Dilihat dari tabel, dengan rentang umur 35-atas tahun berprofesi sebagai tukang ukir dan tukang amplas. Rentang 25-40 tahun berprofesi sebagai ibu rumah tangga, tukang angkat junjung, tukang amplas maupun gerinda (amplas dengan mesin). Sedangkan rentang 18-25 tahun berprofesi sebagai pembuat ice cream, tukang gerinda, serabutan, sekertaris, maupun guru.

Setelah dilakukannya observasi dapat dilihat telah berkurangnya minat dalam meningkatkan potensi yang ada di dalam desa. Keinginan untuk belajar agar dapat menjadi pengusaha sendiri dengan cara menggali potensi diri kurang diminati. Dilihat dari peluang yang ada pada Desa Mulyoharjo harus dapat dimanfaatkan oleh masyarakat sekitar.

Penggalian keterampilan (skill) diri yang disesuaikan dengan potensi desa memberikan rasa aman tersendiri terhadap hal-hal yang tidak diinginkan seperti, jika terjadi pemecatan atau pengurangan karyawan pada suatu tempat industri maka rasa khawatir tidak akan setinggi orang yang tidak mempunyai kemampuan (skill). Orang yang mempunyai atau sudah menggali skill diri tidak akan bergantung pada hanya satu tempat kerja, melainkan dapat memulai usaha sendiri dan mencari tempat lain dengan mudah.

\section{Analisis Kebutuhan Sistem}

Analisis kebutuhan sistem mengacu pada proses bisnis sistem peningkatan potensi desa. Sistem peningkatan potensi desa berisi info dan cara alur pendaftaran. Sistem ini memiliki beberapa proses sebagai berikut :

1. Sistem memberikan info, berita terkait peningkatan potensi desa.

2. Sistem menyediakan proses registrasi untuk pengguna.

3. Sistem menyediakan login.

4. Sistem memberi pilihan keterampilan (skill) yang ingin dipilih oleh pengguna.

\section{PEMBAHASAN}

Untuk melakukan peningkatan potensi desa tidak hanya diperlukan dari masyarakan, namun juga diperlukan kesadaran dari kepala desa yang memberi fasilitas dalam peningkatan potensi desa itu sendiri, untuk itu penting adanya sistem peningkatan potensi desa ini. Selain memberikan pelatihan terhadap masyarakat untuk penunjang pekerjaan, juga menunjang potensi yang ada pada desa. Berikut adalah hasil perancangan 
dan analisis sistem peningkatan potensi desa.

\section{A. Perancangan Data Flow Diagram}

1. Diagram Konteks/DFD Level 0

Diagram konteks adalah diagram yang terdiri dari suatu proses dan menggambarkan ruang lingkup suatu sistem. Diagram konteks merupakan level tertinggi dari DFD (Data Flow Diagram) yang menggambarkan seluruh input ke system atau output dari sistem. Berikut ini adalah diagram konteks Sistem Peningkatan Potensi Desa.

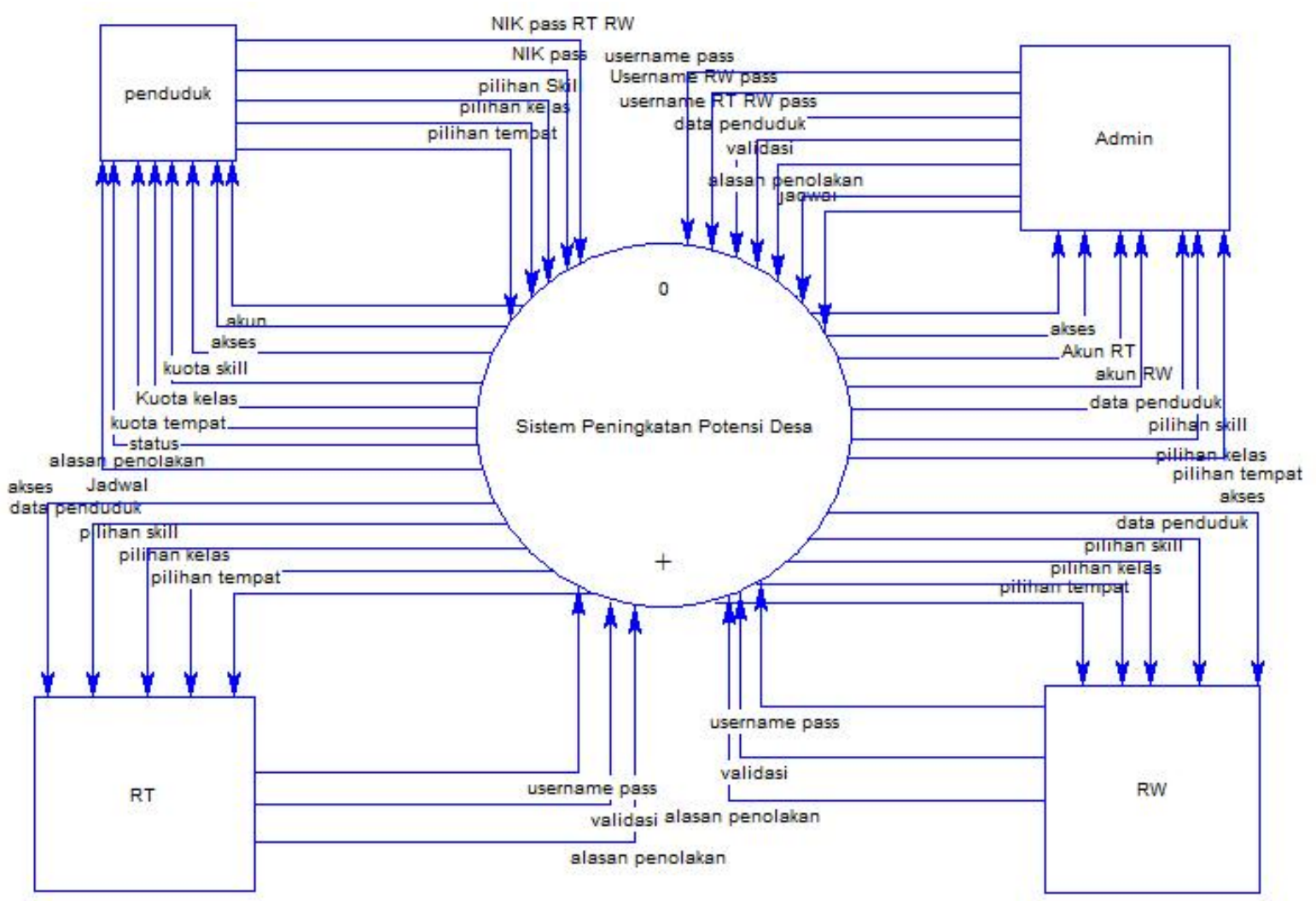




\section{DFD Level 1}

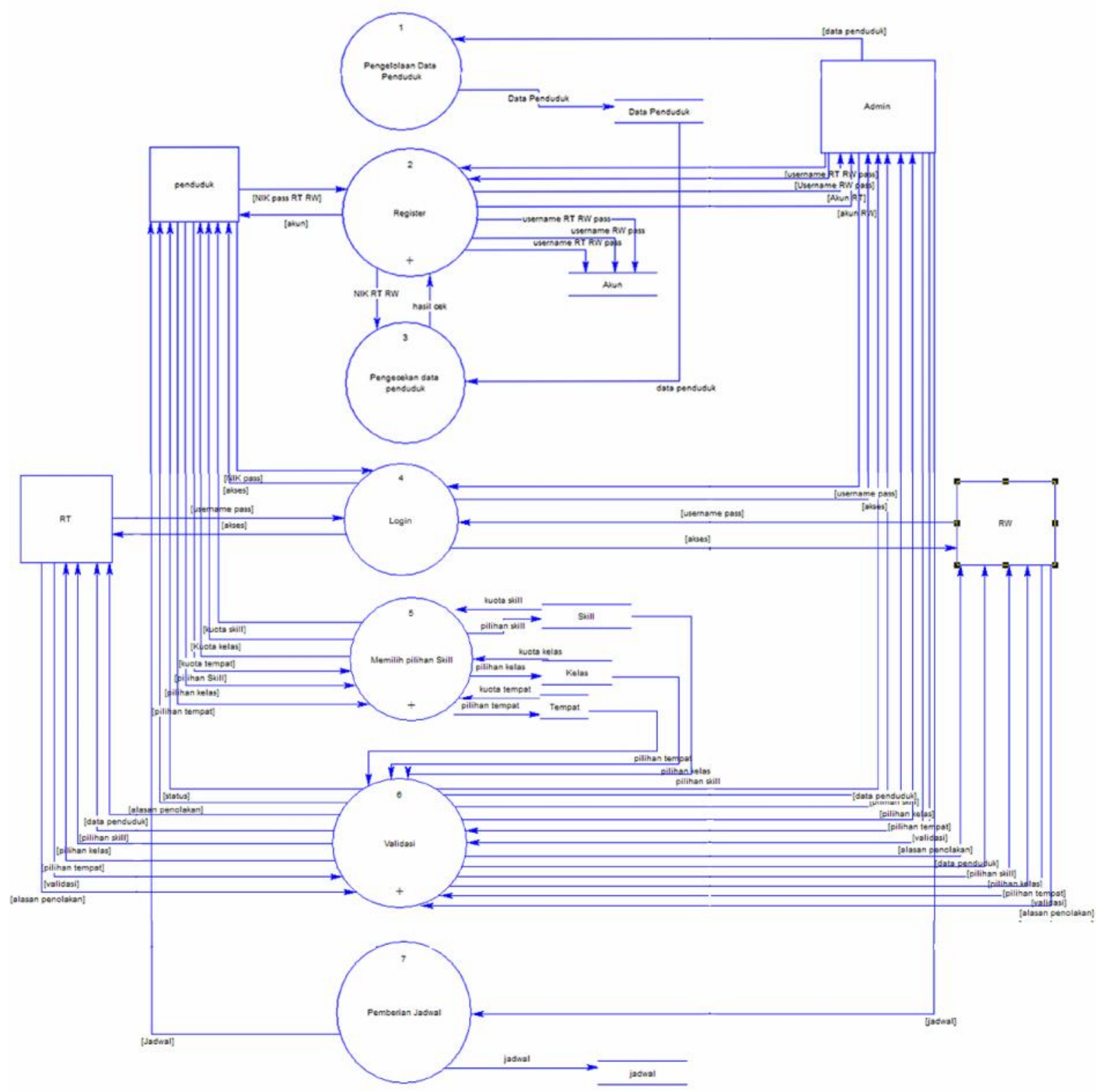


3. DFD Level 2 :

a. Register

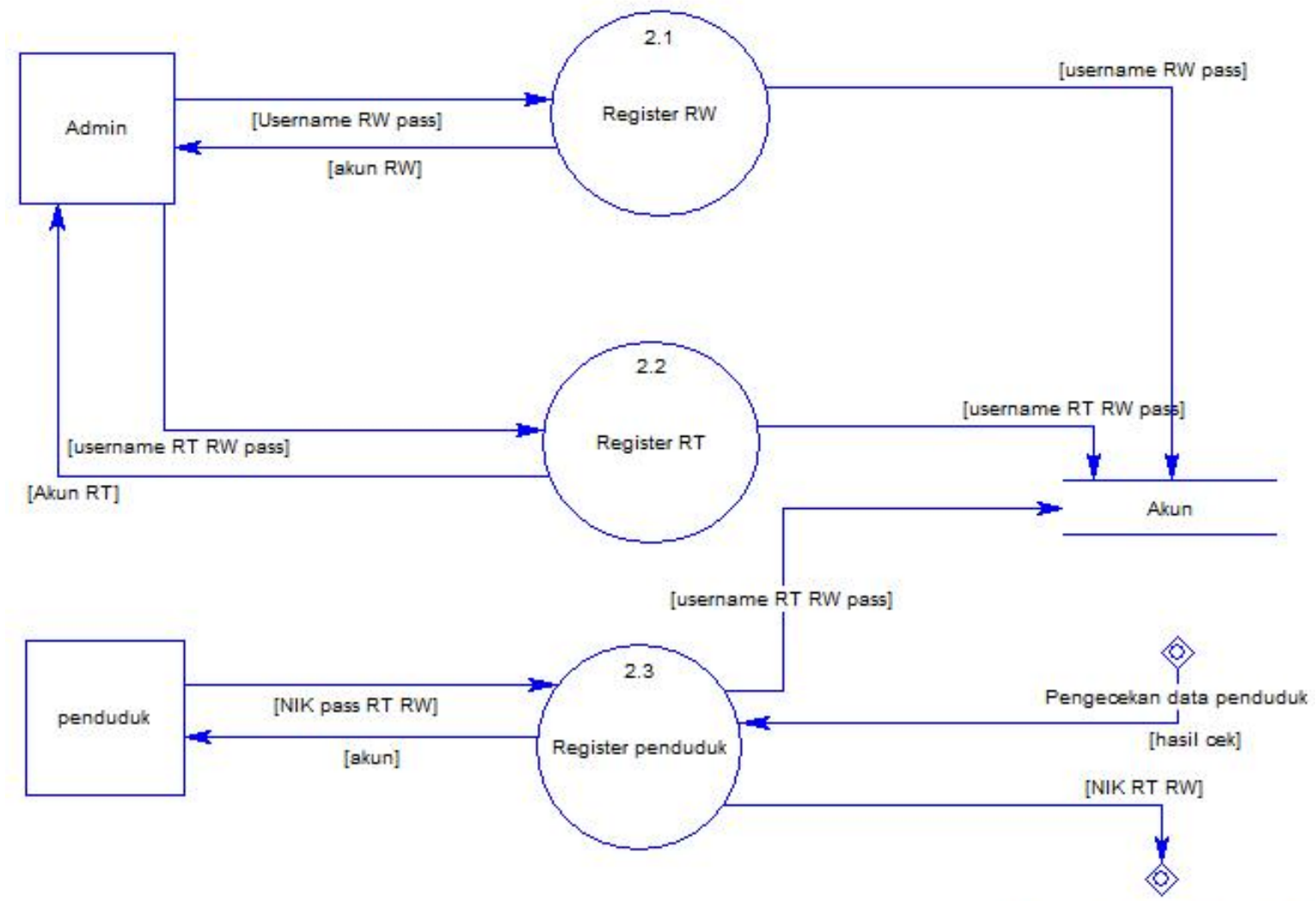

Pengecekan data penduduk

\section{b. Memilih Pilihan Skill}

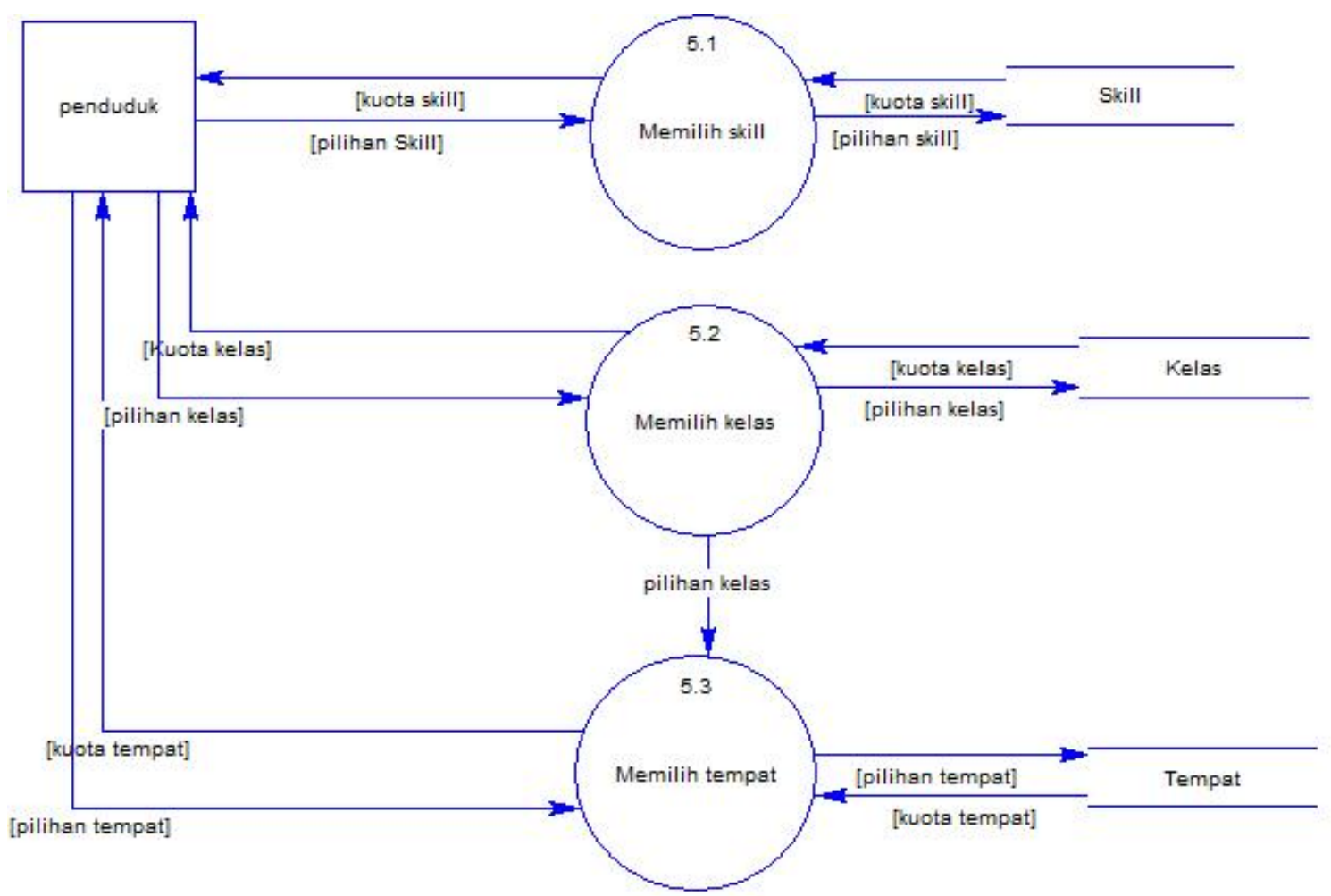




\section{c. Validasi}

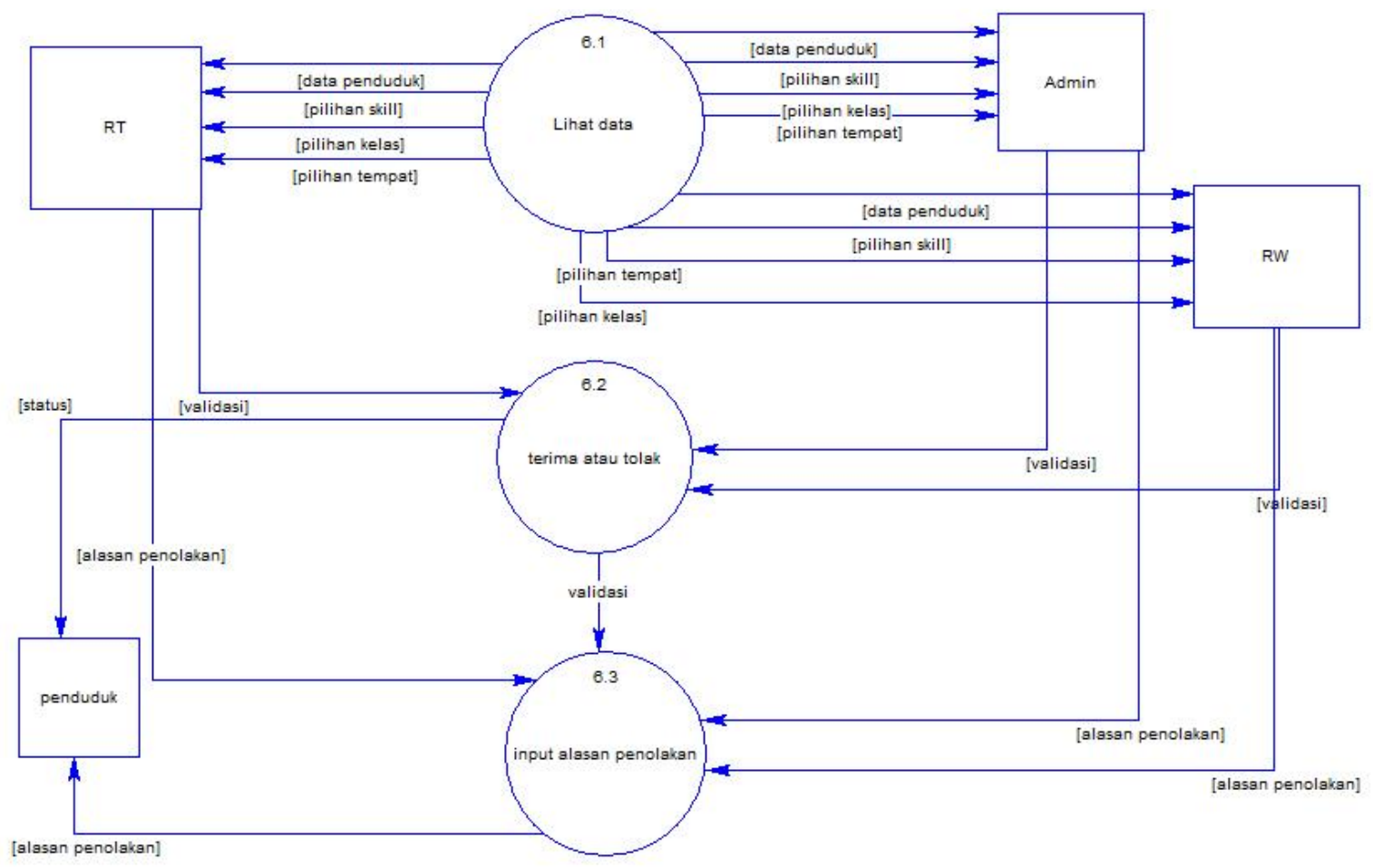

B. Perancangan Database

\section{CDM (Conseptual Data Model)}

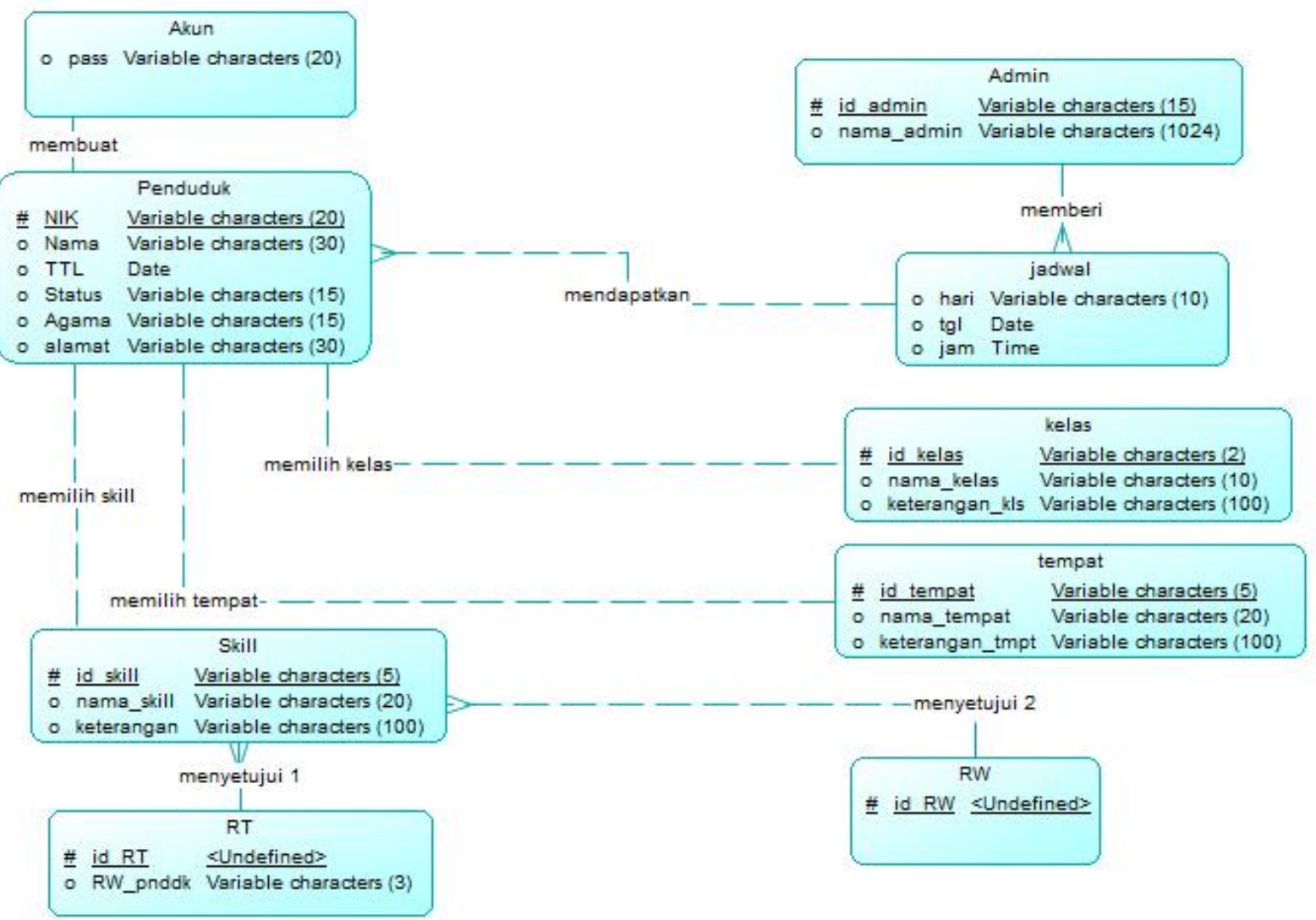




\section{PDM (Physical Data Model)}

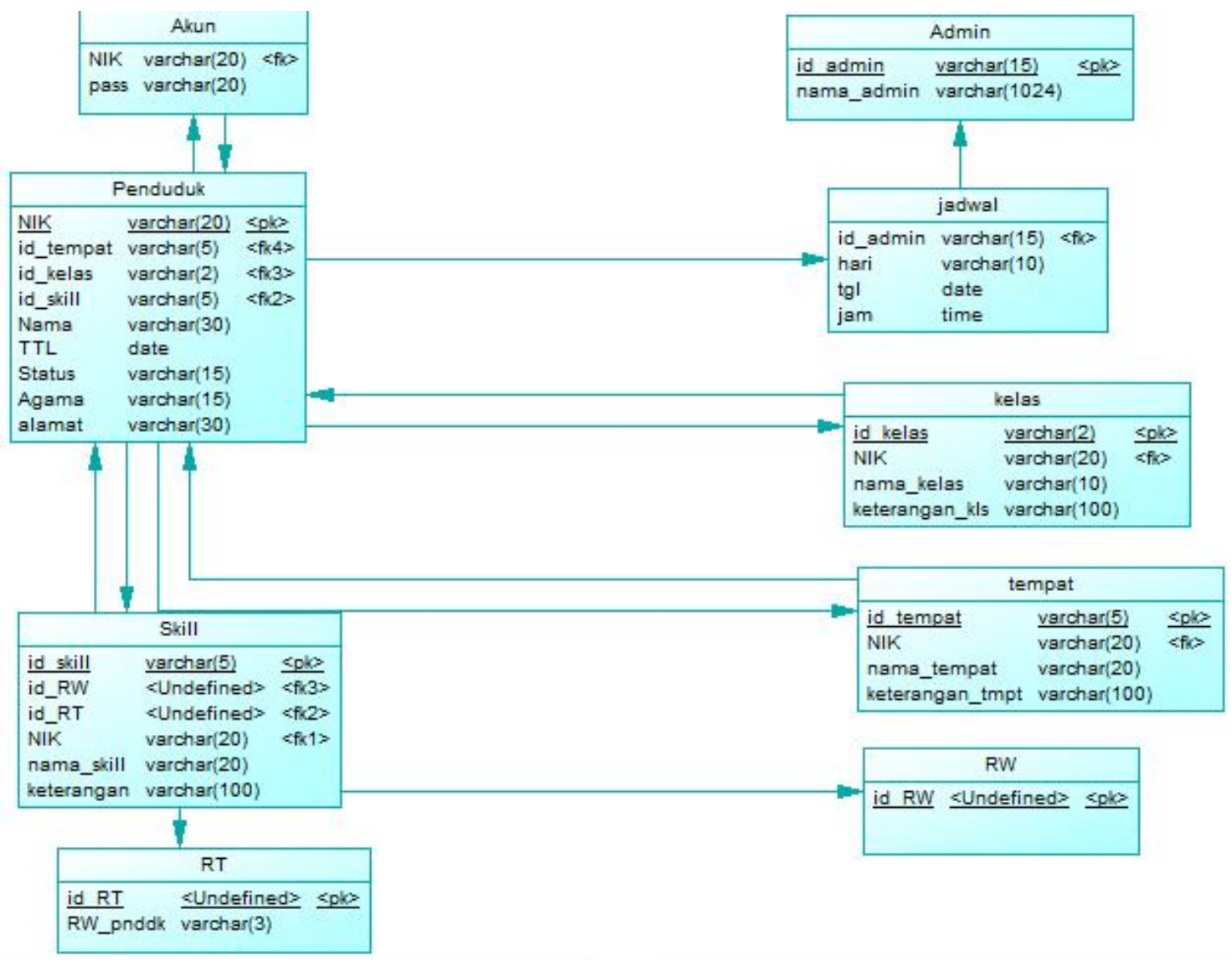

\section{Perancangan Tampilan Sistem}

\section{Login}

Sebelum mendaftar atau memilih skill yang ingin dipelajari penduduk harus melakukan login, register hanya bisa dilakukan oleh penduduk desa yang menggunakan sistem. Penduduk di luar desa tidak bisa menggunakan:

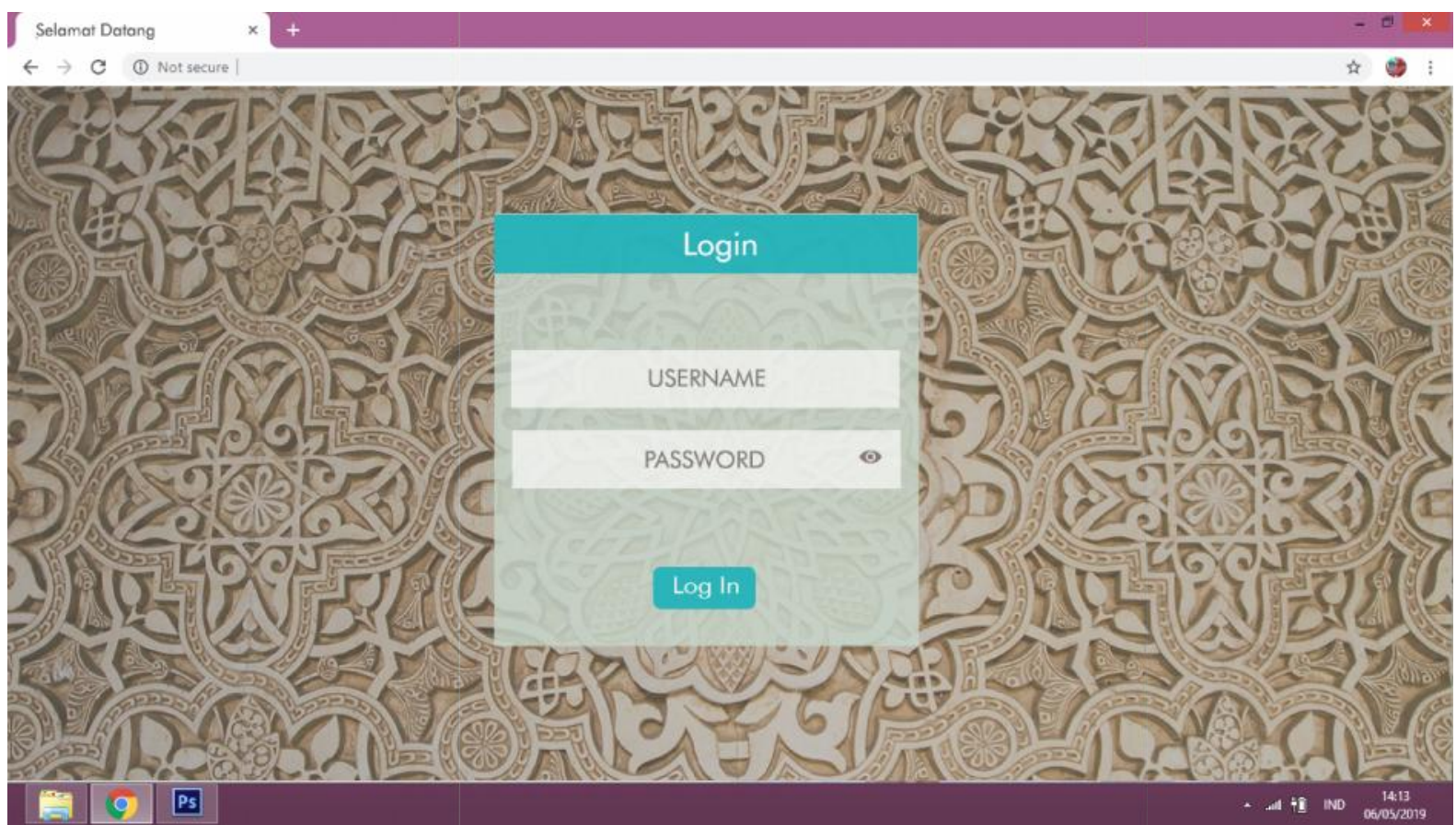


2. Pemilihan Skill

Melakukan pendaftaran skill yang ingin dipelajari.

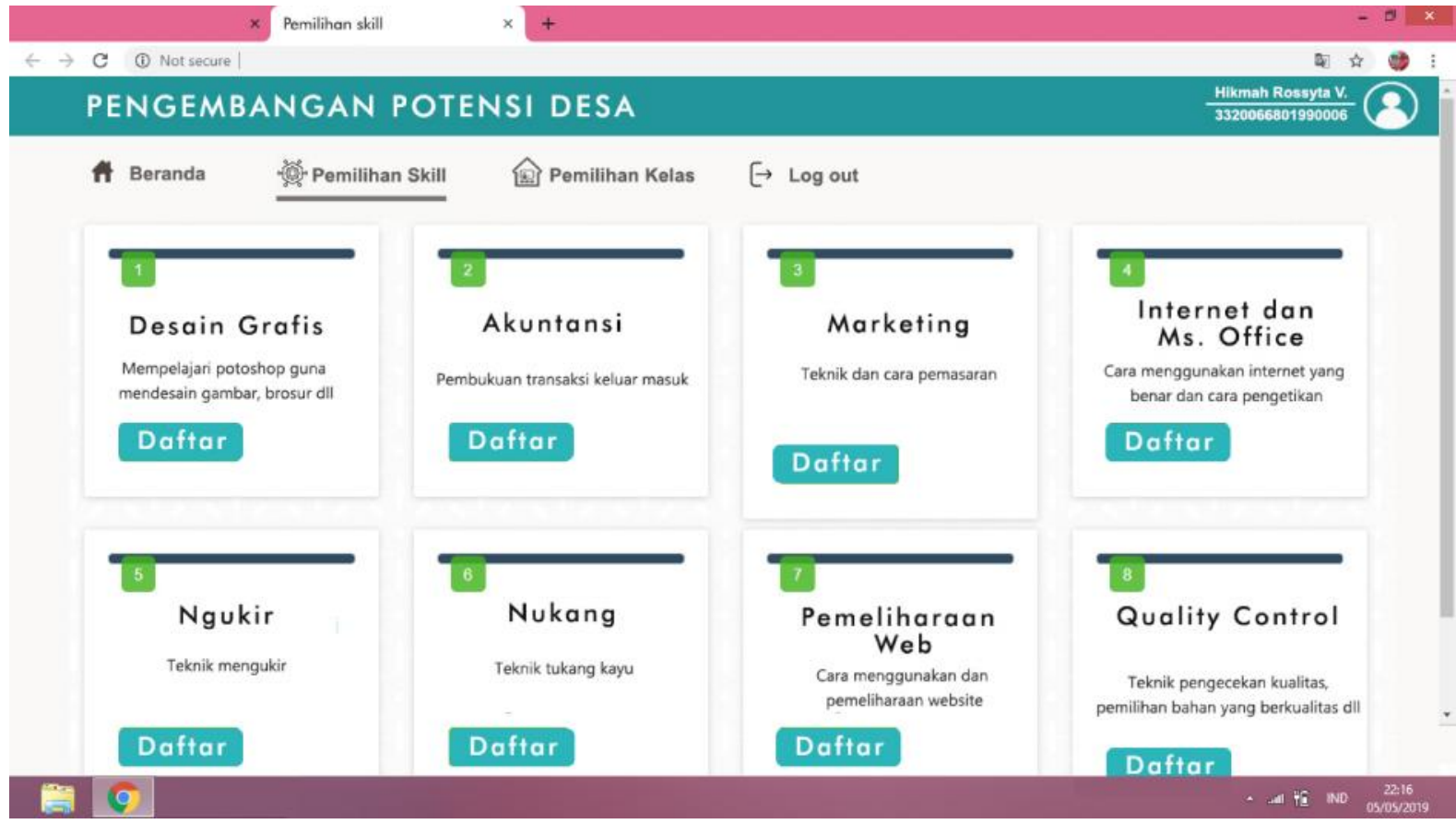

\section{SIMPULAN}

Semakin hari potensi desa bukan semakin bertambah melainkan semakin berkurang, pentingnya menjaga potensi suatu desa tidak hanya menguntungkan bagi desa, melainkan bagi masyarakat itu sendiri. Seperti halnya pada Desa Mulyoharjo Kecamatan Jepara potensi ukir dan furniture yang ada menjadi ciri khas desa, menambah wisatawan yang masuk, menambah pemasukan masyarakat dan lain-lain. Namun peningkatan potensi desa tidak hanya membutuhkan kesadaran sebagian orang melainkan seluruh masyarakat yang terlibat di dalam desa mulai dari Camat/Petinggi, perangkat desa, maupun masyatakat. Dengan adanya sistem peningkatan potensi desa desa dimudahkan dalam melakukan peningkatan potensi desa yang tentu saja diimbangi dengan dilakukannya himbauan oleh desa.

\section{DAFTAR PUSTAKA}

Herry, Antono. (2105). Kesiapan Desa Menghadapi Implementasi UndangUndang Desa (Tinjauan Desentralisasi Fiskal Dan Peningkatan Potensi Desa), Jurnal IImiah CIVIS, Vol. V, No 1 Th 2015.

Zulkarnaen, Reza M. (2010). Pengembangan
Potensi Ekonomi Desa Melalui Badan Usaha Milik Desa (Bumdes) Pondok Salam Kabupaten Purwakarta, Jurnal Aplikasi Ipteks untuk Masyarakat Vol. 5, No. 1, Th 2016

Ibrahim Ali, Rifai Ahmad dan Oktarina Lina (2016). Rancang Bangun Aplikasi Pencatatan Data Kependudukan Kelurahan Pahlawan Berbasis Web. Jurnal Sistem Informasi (JSI), Vol. 8, NO. 1 Th 2016.

Abdurrahman, lqbal. (2010) Analisis dan Perancangan Sistem Informasi. Bandung,.

Ladjamudin, Al-Bahra bin. (2005). Analisis dan Desain Sistem Informasi. Yogyakarta. 